\title{
Retraction of Relationships Between p16 Gene Promoter Methylation and Clinicopathologic Features of Colorectal Cancer: A Meta-Analysis of 27 Cohort Studies (DOI: 10.1089/dna.2013.2253)
}

\begin{abstract}
Ll of The authors of two articles published in DNA and Cell Biology have requested the retraction of this meta$A$ analysis article. The reason they state is "severe conflicts of author sequences."

Chen, Y.-Z. et al. (2014). Relationships Between p16 Gene Promoter Methylation and Clinicopathologic Features of Colorectal Cancer: A Meta-Analysis of 27 Cohort Studies. DNA Cell Biol 33(10):729-738. DOI: 10.1089/dna.2013.2253. Epub 2014 Jun 30.

On PubMed.gov, the abstract is accompanied by a comment from Guillaume Filion indicating that the paper bears striking similarity to other publications.

These authors have also recently retracted three papers, one from Molecular Biology Reports and two from Tumor Biology.

DNA and Cell Biology is dedicated to upholding the strictest standards of scientific publishing, and will not tolerate any improprieties.
\end{abstract}

